\title{
Revision of the Catalog Code
}

Mr. Osborn, chief, Catalog Department, Harvard College Library, read this paper before the Conference of Eastern College Librarians, November 29, I94I.

$\mathrm{T}$ HE THESIS here maintained is a simple one. It is that action on the revised catalog code be deferred at least until the Library of Congress has had time to formulate its rules and practices anew.

Cataloging history is still at the stage where in American libraries the Library of Congress sets the fashion. As long as that stage continues the general cataloging code should follow closely, but not slavishly, Library of Congress usage.

The happy result would be that the Library of Congress might come to find a level of cataloging that large, medium, and small libraries all might follow with a minimum of variation. This is by no means an impossible goal. In fact the leadership now being shown at the Library of Congress points in this very direction.

\section{The Library of Congress and the Anglo-American Code}

In the preface to the preliminary American second edition of the A.L.A. Catalog Rules various reasons are given to show why the Anglo-American code should have been revised so extensively and so radically. In effect, these reasons boil down to one: such revision was deemed necessary to reconcile the 1908 code with Library of Congress practice.

Cataloging history reveals a long story of interplay between the two systems. In I90I the instructions to the Catalog Rules Revision Committee called for a code of rules in agreement with those in force at the Library of Congress. Nevertheless, the published code of 1908 differed from Library of Congress practice in a number of more or less important details. Between 1908 and 1933 the Library of Congress added to its body of rules, with the result that discrepancies multiplied.

Since many libraries were attempting to follow Library of Congress practice, the consequence was that the 1908 code was criticized increasingly often as the gap widened. With such libraries and with library schools that taught the use of L.C. cards, the code could not fail to lose caste and it did this in spite of the fact that it is essentially a very good piece of work.

All through the twentieth century the general tendency has been for libraries to make concessions to Library of Congress cataloging, with a great librarian like Cutter pointing the way. The preliminary American second edition of the catalog code can be regarded as a major concession to the Library of Congress, a statement which should be made with the clear understanding that it has been the desire for the past forty years to have a catalog code that does agree with the Library of Congresss.

In these circumstances, it is germane to ask whether the proposed new code has been successful in realizing this old objective. In the first place, some Library of 
Congress practice is footnoted just as it was in the 1908 code. In general, this is a wise procedure. In the second place, Library of Congress cataloging of the middle thirties was itself divided on many points, a fact well known to libraries which are doing cooperative cataloging and which are familiar with the phrase, the "preferred Library of Congress practice."

For the success of the proposed code, the Library of Congress of 1941 or 1942 would have to adopt these interpretations of its practice, which up to 1940 it was willing to do. In the third place, the code disagrees with or modifies Library of Congress practice of the middle thirties in a number of cases, the more significant of which are anonymous classics, religious headings, and the form of the publisher's name. In a few instances the code states that the Library of Congress of the middle thirties will not change.

In general the new code has been rather successful in setting out Library of Congress practice; but, and this must be emphasized, it records Library of Congress practice as it was prior to 1940 , not as it may be in the immediate future. From the point of view of the editorial committee for the new code, its misfortune was that it had no occasion to suspect that the cataloging situation at the Library of Congress might undergo such a remarkable change as it has since 1940 .

\section{Cataloging in College and University Libraries}

Library of Congress cataloging affects college and university libraries intimately, since they are the largest users of its printed cards. In 1 $938-39$, out of a total of $\$ 297,000$ received by the Card Division at the Library of Congress, no less than $\$ 162,000$ came from college and university libraries (whereas public libraries, by contrast, spent only $\$ 80,000)$. Nine hundred and twenty-five college and university libraries used the card service. Of these, however, 7 I 8 (those with a student body of less than one thousand) spent an average of about $\$ 75$ a year on Library of Congress cards. The remaining 207 (all with a student body of more than one thousand) are the libraries most extensively concerned with the proposed code and its problems.

In spite of the great and increasing use of Library of Congress cards by college and university libraries, the present cataloging needs of these libraries differ very greatly from those of the Library of Congress, which was not the case in I90I. Open access now makes a very great difference to the cataloging program. At least the faculty and graduate students have open access in college and university libraries, while undergraduates have complete access in some cases and limited access in others. With open access, many readers use the catalog only after they have been to the shelves. As a result, fewer subject cards, fewer added entries, and fewer references are needed, while the classification scheme can be regarded as performing many of the functions the card catalog would otherwise be called on to perform. In addition, a great part of the use of a college or university library is through reserve reading rooms, the work of which does not call for reference to the card catalog to more than a slight extent. Further, departmental and similar libraries on a campus are capable of functioning with the methods of the relatively small or special library. This is particularly true when the departmental libraries order and catalog their own books. In fact, some of the best departmental libraries in the 
country have been built up satisfactorily because attention has been concentrated on the acquisition of materials and a minimum of work has been done on cataloging. This was the situation, for example, in the greatest law library in the country which happens to be a departmental library. Again, college and university libraries have made considerable use of self-cataloging methods, particularly for government documents. The cataloging of serials has often been simplified greatly through reliance on serial checklists of one kind or another. In this connection, it might be pointed out that the Library of Congress itself is now in a position to modify and simplify its cataloging of serials in a similar manner, since it is now installing a visible index for its numerous serials.

\section{College and University Libraries and the Code}

Apart from the question as to what extent the Library of Congress and the few similar reference libraries with closed stacks (such as the New York Public Library) need very detailed cataloging, it is clear that college and university libraries do not require detailed cataloging for a large part of their specially organized work. Hence they have less need for as detailed a code as the one that has been prepared. This applies to both parts of the code, although it applies much more to the second part than to the first. Cooperative cataloging does not change the picture. Of the 4I libraries doing cooperative cataloging, 35 are college and university libraries. For this work, the cataloger requires a knowledge of the rules and practices followed by the Library of Congress. But these do not need to be applied any more than is necessary for cataloging that is done purely for local use. College and university libraries would be the losers in the long run if they adopted a detailed code for the sake of cooperative cataloging.

\section{General Comments}

One important change in the cataloging code is in the concept of the author heading itself. The old code attempted to look on the author heading from the point of view of entry words. The proposed new code tends to get away from this idea in a number of respects and to give the author heading a status and importance of its own. It does this by adding new elements to the author heading, whether these are needed or not. This tendency can be observed particularly in the headings for documents and anonymous classics.

The sequence of rules in the old code needed some adjustment, but in general it was effective, particularly for teaching purposes. The arrangement in the new code is very different and may appear to some librarians to be less effective than the old code in several important directions. In this connection, it will be interesting to learn the opinion of library school instructors.

The wording of the code has likewise undergone much change in the process of revision. Again, some librarians may feel that the simpler wording of the 1908 code is often preferable.

The proposed rules allow some variations in practice. They could with advantage be more permissive, especially in such matters as the use of authority cards and the number of added entries and references called for.

Libraries can spend a great deal of time and money, not always to the best advantage, on rules for religious and corporate entries and for serials. This suggests 
that the rules for these items might bear very careful scrutiny to make sure that every detail is really justified.

The second part of the code is likely to come in for more criticism than the first, especially in little matters such as adding the Fascist to the Christian year in the imprint. As far as the detail of the second part is concerned, the Library of Congress may need to determine many details for the printing of its cards when homemade typewritten or multigraphed cards can be made with relatively slight attention to such refinement.

The preliminary American second edition cannot be called the AngloAmerican code. This seems to be a loss in something more than just international cooperation. A certain check and balance for the code may have been lost as well.

The proposed code contains no reproductions of sample cards, although the number of examples included in the text is very great. The sample cards in the 1908 code were assembled rather hastily and unsystematically so that they were never very effective. Perhaps sample cards can be issued in a separate publication. They have considerable value both for teaching and for everyday library purposes.

Library administrators are apt to comment most frequently on the fact that the proposed code does not seem to have made any contribution or concession to simplified cataloging, apart from the simplified rules for cataloging incunabula. The big need of the day is for simplification of cataloging details, together with simplified rules for less valuable books and pamphlets.

\section{Recommendations}

The Library of Congress has spent a year reorganizing its processing divisions. It is only now in a position to begin considering the technical rules of cataloging. Accordingly, it is of first importance to recommend that all action on the code except discussion should be suspended for a year or more until the Library of Congress has had time to review its rules. In this way only can the instructions of 1901 be fulfilled. This interim would give the Library of Congress time to show the leadership in cataloging matters that is now needed of it.

The next recommendation is that the I 908 code should be re-examined carefully. This is not advocated from a conservative or obstructionist point of view. Rather it is to emphasize that there is much that is genuinely good and basically sound in that code. Perhaps the Library of Congress could do worse than follow the old code more than it has done in recent years.

The third recommendation is that all necessary time be allowed to elapse so that the British can cooperate fully in the new code. There is everything to be gained by retaining an Anglo-American code. If such delay means waiting several years, the time can be used to advantage in studying the cataloging needs of various types of libraries and in cooperating in every way possible with the Library of Congress in the formulation of new rules. The preliminary American second edition has changed and expanded the rules so much that a great deal of time is necessary for careful consideration of them. It is not easy to see a way out of the difficulties in which cataloging now finds itself, nor at this stage is it easy to recommend what should be done with the proposed new code.

The special recommendation for college 
and university libraries is that they should re-examine their cataloging program to see whether their present needs coincide with the I90I instructions.

Finally, libraries of various types can see whether their cataloging objectives for the future may not even now be indicating the shape of things to come. For example, the book stock and the card catalog have both grown and have both been given hard treatment for a generation. In the light of these facts, should current cataloging be got in hand so that catalogers could be set free to revise and improve the card catalog? Are libraries relying on card catalogs too much in the care and building up of the book stock? The card catalog is apt to describe a book as it was when it was received in the library. Will the future make increasing demands for a more realistic catalog, for one that is more in keeping with the book collection as it is now rather than as it was at the time of cataloging? Questions of this kind are likely to come up as the book stock shows additional signs of wear. A new code might crystallize cataloging practice for a long time to come, and that possibility suggests the desirability at this stage of an examination of both present and possible future objectives for the card catalog.

\section{Present Developments and the Revision}

It is extremely unfortunate that present developments could not have come before revision of the cataloging code was undertaken. The need for economy has become so urgent that even the fundamental principles on which the American dictionary catalog has been built up are now for the first time being questioned. The revision committee did not do a perfect job but from the technical point of view it produced a first-rate piece of work for which all credit is due. A totally different problem now exists from the one the committee was appointed to meet. The need now is to re-examine all cataloging practice to see what is essential and what nonessential. It really is a case of starting again from scratch. The work that has been done on the code is not lost. It will be turned to with satisfaction when the new objectives are defined.

Real gain is already apparent from the intensified interest that head librarians are taking in their catalog departments. It is a matter of satisfaction to find more than a few administrators inquiring carefully into the revised code and into the cataloging situation in their libraries in consultation with their catalogers. Lasting benefits are sure to come from such developments. 